UDC 616-053.3 DOI 10.22448/AMJ.2017.3.131-133

\title{
ANALYSIS OF OBESPECHENNOSTI VITAMIN D THE CHILD POPULATION OF THE AMUR REGION
}

\author{
E. P. Borisenko, E. B. Romantsova, V. M. Berendeeva
}

\author{
Amur state medical Academy of Minzdrav of Russia, Blagoveshchensk
}

Summary: Epidemiological studies indicate a high prevalence of vitamin $D$ deficiency among children and adult population in different countries $[1-8,10]$. In connection with the numerous studies of foreign authors, which proved the adverse effects on the body vitamin D: the development of autoimmune and inflammatory disorders, cancer (mammary, pancreas, prostate gland, intestine and colon), heart failure, hypertension, myocardial infarction, diabetes mellitus, obesity. In connection with the urgency of the problem of insufficient content of cholecalciferol in the blood of children, a survey of 229 children of different ages. This study is a fragment of a multicenter, prospective, cohort, pharmacoepidemiological studies assessing the provision of child population younger age group vitamin $D$ in the Russian Federation "SPRING". The results of study of vitamin D metabolites in serum of healthy children from 3 to 6 years, adolescents aged 15-17 years living on the territory of Amur region. These results allow to speak about necessity of revision of existing methodological recommendations taking into account modern approaches to the prevention and treatment of deficiency with different degrees of severity of vitamin $\mathrm{D}$ in children and adolescents.

Key words. children, risk factors, vitamin D insufficiency, frequently ill children.

Introduction. Up to the present time vitamin $D$ was associated within the meaning of the doctor effect on bone-joint system, for the prevention/treatment of rickets in children the first year of life $[3,5,6,7]$. In the present study, D - deficient States in children has become an urgent problem worldwide. In recent years, were discovered and collected convincing data on the role of vitamin $D$ in many other biological processes.

The study multicenter, prospective, cohort, pharmacoepidemiological studies assessing the provision of child population younger age group vitamin D in the Russian Federation "SPRING" participated 1230 children aged from 1 month to 3 years in 11 cities of Russia. The analysis of this study showed that only every third child was determined normal vitamin D levels $(>30 \mathrm{ng} / \mathrm{ml})$. $300(24,4 \%)$ children revealed a lack of cholecalciferol in blood plasma $(20-29 \mathrm{ng} / \mathrm{ml})$, deficiency of $25(\mathrm{Oh}) \mathrm{D}<20 \mathrm{ng} / \mathrm{ml}$ was observed in $513(41,7 \%)$ [2,3]. Among all surveyed children in Russia under the program "the spring" $(n=1230)$ there was not a single result above the upper limit of normal.

In the course of research in the Department of Pediatrics GBOU DPO RMAPO MOH Russia under the leadership of Professor Zakharova I. N. in 2013-14 the surveyed children, aged 10-17, Moscow results seasonal changes of vitamin D in the serum to demonstrate the relationship of this vitamin from the month of the year. The lowest concentration of vitamin $D$ was observed in may, and a more favorable picture in the summer-autumn period than in winter-spring $[9,10,12]$.

A recent study of teenagers living in the Amur region, found in $26,2 \%$ of patients low in vitamin $D$, a higher level was observed in adolescents living in rural areas [8].

The Department of Pediatrics of the Amur state medical Academy MZ of the Russian Federation in 2014 was organized by the research assessment provision for children 3-6 years boys 15-17 years of vitamin D in the Amur Region.

The goal is to study the availability of vitamin $D$ in children of different age and adult population of Amur region.

Materials and methods. Study on the identification of D-deficiency States in children and the adult population started from November 2013 to March 2015.

Criteria for inclusion of patients in the study: healthy children (1 month- 3 years, 3-6 years, $15-17$ years) residing in the Amur region.

Exclusion criteria: rickets, mental disorders, disorders of hepatic function and renal function.

The content of the metabolite of vitamin $\mathrm{D}[25(\mathrm{Oh}) \mathrm{D}]$ in blood serum was determined by high-performance liquid chromatography analyzer Liason Dia Sorin Pleutschland GmbH Germany, sn - 22290044. The vitamin D took the level of $25(\mathrm{Oh}) \mathrm{D}=30-100 \mathrm{ng} / \mathrm{ml}$, insufficiency-20-29 ng/ml; deficiency<20 ng/ml [1].

The obtained results were statistically processed with the use of applied programs Statistica 6.0.

Results and discussion the obtained data.

The data obtained for the city of Blagoveshchensk in the result of a multicenter, prospective, cohort, pharmacoepidemiological studies assessing the provision of child population younger age group vitamin D in the Russian Federation "the SPRING" (2013-2014). In the group of healthy children from birth to 3 years was 129 children. In the analysis of laboratory data examined 25(Oh)D. In the group from birth to 6 months 24 children breastfed, the average age in months was $2.63 \pm 0,27$ average $25(\mathrm{OH}) \mathrm{D}$ was $34,12 \pm 4,9 \mathrm{ng} / \mathrm{ml}$. Vitamin $\mathrm{D}$ in the normal range $(30-100 \mathrm{ng} / \mathrm{ml})$ were detected in 11 $(45,8 \%)$, insufficiency was detected in $6(25 \%)$, the deficit in $3(12,5 \%)$, a marked deficit in $4(16,6 \%)$. In the group with artificial feeding 24 children the average level of $25(\mathrm{Oh}) \mathrm{D}$ was $41.7 \pm 3.3 \mathrm{ng} / \mathrm{ml}$, figure calzidiola in the normal range - 11 (54.1 per cent), failure was detected in $6(25 \%)$, the deficit in $5(20,8 \%)$, a marked deficit in $2(8,3 \%)$. Overall, in the group of 
children from birth to 6 months ( $n=48$ ) level of vitamin $D$ is $32,54 \pm 3,24 \mathrm{ng} / \mathrm{ml}$. In the group with 6 months to 1 year $(n=27)$ level of $25(\mathrm{Oh}) \mathrm{D}=$ of $39.75 \pm 5,36 \mathrm{ng} / \mathrm{ml}$, within the normal range $-14(51,8 \%)$ and insufficiency in $6(22,2 \%)$, the deficit in $5(18,5 \%)$, a marked deficit in $2(7,4 \%) .26$ children 1 to 2 years of age the level of $25(\mathrm{Oh}) \mathrm{D}$ was of $24.10 \pm 3,6 \mathrm{ng} / \mathrm{ml}, 4$ $(14, \%)$, his failure was noted in 9 (34.6 per cent), the deficit in 8 patients $(30,7 \%)$, with a pronounced deficit in 4 (15.3 per cent). In 28 children with 2 to 3 years of age the level of $25(\mathrm{Oh}) \mathrm{D}$ made up of $19.31 \pm 14,68 \mathrm{ng} / \mathrm{ml}$, the rate was observed in 1 (3.57 per cent), failure was detected in $13(46,4 \%)$, the deficit in 12 (42.8 percent), severe deficit 3 (10.7 per cent).

Analysis of vitamin D, 30 children 3 - 6 years showed that $17(56.7 \%)$ of children identified normal levels of $25(\mathrm{OH}) \mathrm{D}$, 13 children (43.3 per cent)- insufficient level of $25(\mathrm{OH}) \mathrm{D}$. In this group the average was $25(\mathrm{OH}) \mathrm{D} 30,54 \pm 0,97 \mathrm{ng} / \mathrm{ml}$, which is the lower limit of normal.

Thestudyin thegroup of healthyteenagersand60 children, students of the Amurcorps of cadets, 15-17years, itwasrevealed that7 ofTeens (11,6\%) level of 25(OH)D withinnormallimits, andin53(88,3\%) wasnotedforvitamin Dinsufficiency, inthesubgroup with deficiency of 25(OH)Dincluded 14 cadets (23.3 percent). Theaverage25(OH)Dinallexamined23,89 $\pm 0,66 \mathrm{ng} / \mathrm{ml}$.

Obtained in the course of the study, the results indicate a high frequency of failure and vitamin D deficiency in a group 3 years of life $(92,43 \%)$ children $15-17$ years $(88,4 \%)$ and 2 years of life (for $84.7 \%)$. The highest calzidiola found in the group of healthy children 3-6 years (56.6 per cent), slightly less in children from birth to 6 months $(45,8)$. The increase in reliability with age in the development of vitamin D deficiency and to predict FR in the group have young children, allowing you to include this criterion as predicting factors for having children in the first 3 years.

Conclusion. Analyzing the data of studies ofvitamin Dinyoung children, 3-6years, 15-17years and adults in the Amur region, it can be argued that the results indicate a high frequency of failure and deficiency of cholecalciferol in the Amur region.

Overall, the average vitamin $\mathrm{D}$ level among the local population in the age aspect were as follows: children 1 year of life $36,14 \pm 24,1 \mathrm{ng} / \mathrm{ml}, 2$ years $-24,1 \pm 3,6 \mathrm{ng} / \mathrm{ml}$, 3 years was $19.31 \pm 1.0 \mathrm{ng} / \mathrm{ml}, 3-6$ years $-21,77 \pm 0,96 \mathrm{ng} /$ $\mathrm{ml}, 15$ to 17 years-23,89 $\pm 0,66$. Among children with sufficient vitamin $\mathrm{D}$ level was observed in $31.8 \%$ of children in the first 3 years of life, in $68.2 \%$ ( $2 / 3$ children) identified inadequate supply of vitamin D. the lowest rate is seen in children 3 years, 3-6 years, adolescents aged 15-17 years, with age, the calzidiola content in the body decreases. Significant deficiency identified in $21.4 \%$ of cases in children from birth to 6 months.

Thus, in the result, more than $2 / 3(62,8 \%)$ infants in the Amur region revealed a lack and scarce of availability of cholecalciferol. Similar results were obtained during a multicenter cohort study FONTANEL confirms that more than $2 / 3$ of the younger age group had deficient and insufficient vitamin $D$ in all examined regions of the Russian Federation $[2,3,12]$.

Conclusions. Thus, during a large-scale study demonstrated the prevalence of vitamin $D$ the child population in different age periods, the estimation of informational significance of factors that contribute to the reduction of vitamin $D$ in healthy children of different ages.

To prevent low vitamin D children from birth and throughout life, one must examine the 25(OH)D, its correction and control risk of developing deficiency of vitamin D.

\section{Literature}

1. Holick M. F. Vitamin D deficiency. N. Engl.J. Med. 2007; 357:266-281.

2. Zakharova I. N., Maltsev S. V., Borovik T. E., etc. /Insufficient vitamin D in young children in Russia: results of multicenter cohort study FONTANEL (2013-2014)// Issues of modern Pediatrics. 2014. - Vol. 13. - No. 6. P. 30-34.

3. Zakharova I. N., Maltsev S. V., Borovik T. E., etc. results of a multicenter study "Rodnichok" study of vitamin D deficiency in children of early age// Pediatrics. 2015. Vol 94. - No. 1. P. 62-67.

4. Borisenko E. P., Romantsova E. B., A. F. Babcia /Features D-deficient States in children living in the Amur region//Actual problems of health of children and adolescents: a compilation of scientific articles to the 85th anniversary of DUGA: Khabarovsk: Publishing house of DUGA, 2015. - P. 21-27.

5. Vitebsk A. V., Smirnova G. E., Ilin, A. V. Vitamin D and indices of calcium-phosphorus metabolism in children living in an average strip of Russia, in the period of maximum insolation. Osteoporosis and osteopathy. 2010; 2: 4-9.

6. Smirnova G. E., Vitebsk, A. V., Shmakov N.. The role of vitamin D in the development of the child's body and correction of its deficit. Current concepts]. App Pediatrics. 2010;34: 7-12.)

7. Heaney, R. P. Assessing vitamin D status. Curr. Opin. Clin. Nutr. Metab. Care. 2011; 14 (5): 440-444.

8. Evseeva G. P., Shop O. Yu., Tokarev N.. Uchakina R. V., Efimenko M. V., Vuchkov K. K., Belov N. In. The whole E. D., Suprun S. V., Kozlov V. K. supply of vitamin D children and adolescents in Priamur'e// family Health-the 21,2014.T.4. No. 3.With. 23-35.

9. Hayes CE, Nashold FE, Spach KM, Pedersen LB. The immunological functions of the vitamin D endocrine system. Cell Mol. Biol. (Noisy-le-grand). 2003; 49 (2): 277-300.

10. Lee J. M., Smith J. R., Philipp, B. L., Chen T. C., Mathieu J. and Holick, M. F. 2007. Vitamin D deficiency in a healthy group of mother and newborn infants.Clin. Pediatr. (Phila) 46:42-44.

11. Modern Novikov P. V. rickets: classification, methods of diagnosis, treatment and prevention: a Handbook for physicians. 
Moscow: Moscow scientific and research Institute and DH, 2007: 12-25.

12. Gromova O. A., Torshin I. Yu. Vitamin D is changing pradigm//Under edit. Acad.RAS E. I. Guseva, Professor Zakharova I. N.// Moscow 2015.-S. 373-378.

Borisenko Elena Pavlovna PhD, assistant Professor of Pediatrics DEPARTMENT AT the Amur state medical Academy of Minzdrav of Russia, elena-pavlovna.b@mail.ru. Tel 89638006777

\title{
UDC 61 DOI 10.22448/AMJ.2017.3.133-133
}

\section{CLINICAL CASE OF RELAPSING IDIOPATHIC DISCEMNATED ENCEPHALOMIELITIS}

\author{
Karnauh V.N., Cherednichenko O.A., e-mail: v.n.karnauch@rambler.ru \\ Amur State Medical Academy, Blagoveshchensk, Russian Federation
}

Abstract. Acute disseminated encephalomyelitis (ADEM) is an autoimmune inflammatory disease of the nervous system which can be characterized as widespread demyelization of the brain and spinal cord, which usually develops after infection orvaccination. ADEM takes a special place among the most frequent and severe forms of disseminated encephalomyelitis. In itspathogenesis, aswellasin disseminatedsclerosis, an importantroleisheld byautoimmune reactionstomyelinantigens.

Atypical pathologicalADEM processismonophasic, i.e.acutewithlaterrecovery, which isthemain diagnosticmeasure, which makes it possible to distinguish it from multiple sclerosis. ADEM is manifested by severe encephalopathy with pronounced cerebral and focal symptoms. In some cases, it's possible to see the recurrence of the disease, with an exact reiteration of the first attack symptoms, this is a recurrent ADEM. Rarely, there is possibility of ADEM re-attack, which manifests itself by the involvement of new brain areas and, of course, new clinical symptoms appearance, this is called multiphase ADEM.

Objective. Analysis of the clinical case.

Materials and methods. Literature analysis, clinical records.

Here is an example of observation of the patient with recurrent ADEM.

Patient G., female, 44 years old. By reason of the developed right-sided hemiparesis was taking treatment for ischemic stroke in the primary vascular center. On brain CT - there is hypodensitive area in the right parietal-temporal region. Released with improvement. In 2 months, weakness in the right limbs came back, also there was a walking shakiness. Examinated in the regional vascular center - in addition to focal symptoms as right-sided hemiparesis and static locomotor ataxia, attention was attracted by the presence of euphoria and decrease of criticism and cognitive functions. There was carried out a complex examination. On the brain MRI large pocket of demyelination in white matter, mainly periventricular were revealed. ADEM diagnosis was established, on the pulse therapy with methylprednisolone there was positive dynamics. MRI monitoring in 2 months - pockets reduction. In 4 months - the focal symptoms re-entered, there were bouts of short-term loss of consciousness without seizures. On MRI - decrease of the "old" pockets volume and a new one was revealed in the left temporal region. Considering the disease flow and examinations, the diagnosis is a multi-phase ADEM. Under the pulse therapy with glucocorticoids, there is positive dynamics, but cognitive and emotional disorders persisted.

Conclusion. Despite the development of ADEM criteria, there are difficulties in its diagnosis, especially in the recurrent cases. It is necessary to carry out a differential diagnosis with systemic diseases, chronic neuroinfections and disseminated sclerosis. The study of the anamnesis, clinical and MRI-monitoring allows to clarify diagnosis, as it was in the given case.

UDC 616-002.5 DOI 10.22448/AMJ.2017.3.133-134

\section{INDICATORS OF MORBIDITY AND MORTALITY OF TUBERCULOSIS IN THE AMUR REGION.}

\author{
Goryacheva S.A., Voitsekhovsky V.V., Prikhodko O.B., Kostrova I.V.
}

Amur state medical academy, Blagoveshchensk, Russian Federation

Abstracts. In the Amur Region, as well as in Russia as a whole, there is a stabilization of the epidemic situation in tuberculosis with a tendency to improve it. The level of incidence of tuberculosis is fairly objective. The decrease in the incidence of tuberculosis is taking place against the background of improving the organization of preventive examinations for tuberculosis and reducing the proportion of neglected forms of tuberculosis among newly diagnosed tuberculosis patients. Tuberculosis remains one of the most urgent medical and socio-economic problems. Despite the vast experience of mankind in the fight against tuberculosis, including affordable and effective treatment, 9 million new cases of tuberculosis and almost 2 million deaths from it are registered annually in the world.

Keywords: tuberculosis, morbidity, mortality.

In the modern period, one third of the world's population is infected with a pathogen of tuberculosis, of which 5-10\% become sick. Every year, 2-3 million people die from tuberculosis in the world. In the Amur Region, from 2012-2016, the incidence of tuberculosis was 87.8 persent 100,000 population, and the death rate was 20.88 percent 100,000 population.

Material and methods. We have analyzed the accounting and reporting documentation for the period from 2012 to 